\title{
Análise do uso de objetos materiais mediacionais em uma aula investigativa de Ciências de cunho sociocientífico nos anos iniciais do Ensino Fundamental
}

Leandro da Silva Barcellos leandrobarcellos5@gmail.com orcid.org/0000-0002-8912-3052 (UFES), Vitóla, Espito Santo, Branto

Geide Rosa Coelho

geidecoelho@gmail.com orcid.org/0000-0001-5358-9742 Universidade Federal do Espírito Santo (UFES), Vitória, Espírito Santo, Brasil

\section{RESUMO}

Esta pesquisa tem como objetivo analisar a mediação pedagógica de um professor, em uma aula investigativa de Ciências de cunho sociocientífico, com relação as suas ações com objetos materiais mediacionais. Para tanto, realizamos um estudo de caso a partir do desenvolvimento de uma sequência de ensino investigativa realizada no segundo semestre de 2016, em uma turma do quinto ano do Ensino Fundamental de uma escola da rede municipal de Vitória no Espírito Santo. A intervenção pedagógica abordou o tema "interação radiação ultravioleta-corpo humano" que possui caráter transversal e sociocientífico, estabelecendo, portanto, uma interlocução com os pressupostos do enfoque Ciência, Tecnologia e Sociedade. Para a produção de dados, utilizamos a videogravação de uma aula intitulada "A Luz Negra" que tinha como atividade central uma demonstração investigativa. A atividade buscava problematizar os diferentes produtos de proteção à exposição ao sol. A gravação foi transcrita e analisada qualitativamente por meio da interlocução com autores do campo da educação em Ciências que se ancoram na teoria da ação mediada de Wertsch para discutir a relação entre a utilização de ferramentas culturais e seus significados no contexto da ação docente. Os resultados sinalizam para a ausência de ressignificações dos objetos materiais mediacionais, a qual associamos ao caráter sociocientífico da atividade. Isso levou o professor a delimitar as possibilidades de ação com os objetos para que não houvesse ressignificação, pois intencionava problematizar e discutir tecnologias presentes no cotidiano dos alunos para estabelecer uma aproximação com a realidade social deles. Consideramos que os resultados desta pesquisa podem auxiliar no processo de reflexão sobre o uso de recursos materiais que potencializam o trabalho docente em aulas envolvendo temas sociocientíficos.

PALAVRAS-CHAVE: Ensino de Ciências. Anos iniciais do Ensino Fundamental. Objetos materiais mediacionais. Ação mediada. Meios mediacionais. 


\section{INTRODUÇÃO}

A comunidade de educação em Ciências tem assumido a alfabetização científica como pressuposto para o trabalho docente, reconhecendo a necessidade de um ensino de ciências que forneça não apenas noções e conceitos, mas também condições para que os alunos possam "fazer ciência". Além disso, almeja-se fomentar o interesse dos aprendizes por questões que envolvam a relação entre Ciência, Tecnologia e Sociedade (CTS), estimulando o processo de reflexão sobre as ações antrópicas e o posicionamento crítico (GUISSO, 2018; SASSERON; CARVALHO, 2008).

Os autores brasileiros que assumem esse objetivo educacional para o ensino de Ciências têm utilizado pelo menos três expressões para designá-lo: alfabetização científica, letramento científico e enculturação científica (SASSERON; CARVALHO, 2011). Reconhecemos essa pluralidade semântica e, em nossas pesquisas, temos utilizado o termo enculturação científica, ancorados em pesquisadores como Driver et al. (1999) e Carvalho (2013a). Isso porque partimos do pressuposto de que a Ciência é uma cultura, e que a aprendizagem em Ciências está relacionada à iniciação dos estudantes nas ideias e práticas da comunidade científica. Assim, compreendemos a aprendizagem em Ciências como sendo um processo de introdução dos estudantes na cultura das Ciências (DRIVER et al., 1999).

No processo de enculturação o professor precisa disponibilizar para os alunos as ferramentas culturais da comunidade científica, conduzindo-os no processo de apropriação dos modelos, reconhecimento de seus domínios e aplicabilidades para que eles sejam capazes de utilizá-los.

Nessa perspectiva, o ensino de Ciências que visa a enculturação deve buscar a apropriação, por parte dos estudantes, dessas ferramentas, por meio das interações sociais na sala de aula, que são mediadas pela utilização de meios mediacionais, como a linguagem e as próprias ferramentas. Para Wertsch (1999) a materialidade é uma propriedade de qualquer meio mediacional e, em relação à forma como ela se sustenta, podemos classificá-la como sendo instantânea, temporária ou permanente. Neste estudo enfocamos nos meios mediacionais de materialidade permanente, que são aqueles que "permanecem existindo mesmo depois que os agentes que os usaram desapareceram" (WERTSCH, 1998 apud OLIVEIRA; SÁ; MORTIMER, 2019, p. 254).

No contexto de uma sala de aula, podemos citar, como exemplos, quadro negro, livros didáticos, tabela periódica, projetor multimídia, entre outros. Ancorados em Oliveira, Sá e Mortimer (2019) vamos nos referir a esses meios também como objetos materiais mediacionais, com o intuito de ratificar nossa ênfase nesses meios que permanecem existindo mesmo quando não estão sendo utilizados em mediações. Isto porque esses objetos são, por vezes, utilizados por professores, juntamente com a linguagem, cuja materialidade é instantânea, no trabalho com vistas à enculturação científica dos estudantes.

Wertsch (1999) sinaliza para a existência de uma tensão irredutível entre os indivíduos e os meios mediacionais que eles empregam, sendo inadequado desatrelar a ação dos meios utilizados para mediá-la. Para esse autor, a ação e os 
meios mediacionais estão imbricados, dessa forma, é conveniente falar de agentes-agindo-com-meios-mediacionais.

Isto posto, para discutir a mediação de um professor utilizando meios mediacionais de materialidade permanente no processo de enculturação de alunos em uma aula de Ciências, precisamos levar em consideração o contexto no qual o ato ocorreu e o propósito.

Oliveira, Sá e Mortimer (2019) afirmam, com base nos trabalhos de Vigotski e Wertsch, que o uso de objetos mediadores pode ser caracterizado como ação mediada, ao passo que Pereira e Ostermann (2012) reconhecem que esta é a unidade de análise ideal para o estudo do funcionamento humano, visto que todas as ações empregam ferramentas culturais disponíveis em determinados contextos socioculturais.

Diante desse cenário, propomo-nos a analisar a mediação pedagógica de um professor, em uma aula investigativa de Ciências de cunho sociocientífico, com relação as suas ações com objetos materiais mediacionais.

Escolhemos esse contexto porque entendemos que o ensino por investigação é uma abordagem didática que contribui com o processo de enculturação. Por conseguinte, partimos do princípio de que os estudantes podem ser inseridos na cultura das Ciências quando se depararem com situaçõesproblema nas quais o conhecimento científico é requerido e avaliado na busca pela solução, que promovam uma mobilização intelectual e disparem o processo de investigação científica. Esse processo envolve elementos como: a elaboração e teste de hipóteses, coleta e análise de dados, debates a partir de múltiplas interpretações e socialização de resultados, sempre atuando em parceria com o professor (SÁ et al. 2007; CARVALHO, 2018).

Assumir uma mediação balizada por uma situação-problema adequada e relevante para os alunos possibilita a criação de um ambiente investigativo em sala de aula, tornando-a um espaço no qual os estudantes podem compartilhar experiências, informações e conhecimentos uns com os outros e com o professor, criando um relacionamento rico em diálogos, debates e discussões, potencializando o desenvolvimento não apenas de conceitos, mas também de atitudes e procedimentos típicos da Ciência escolar, promovendo a introdução dos estudantes na cultura científica (BARCELLOS et al., 2019; BARCELLOS; COELHO, 2019; COELHO; AMBRÓZIO, 2019).

Cabe ao professor propor atividades que estimulem o pensamento críticoreflexivo e que propiciem a elaboração de diversas estratégias para a solução do problema, além de potencializar o desenvolvimento de atitudes relativas ao respeito às diferentes ideias e pensamentos, permitindo que os alunos socializem de maneira democrática. Por isso, situações-problema que envolvem temas sociocientíficos podem contribuir para o desenvolvimento de habilidades de pensamento crítico-reflexivo e tomada de decisão por parte dos estudantes, pois abrangem a formação de opinião e escolhas individuais e coletivas, que podem ter relação com questões de relevância local, nacional e até global (BARCELLOS, 2017).

Perante o exposto, optamos por analisar uma aula que é parte de uma intervenção que abordou de forma investigativa o tema "interação radiação ultravioleta (RUV)-corpo humano". Na aula em questão foi feita a 
problematização dos produtos mais comuns utilizados pela população e que tem relação com a exposição ao Sol (protetor solar e bronzeador). A partir dessa problemática, as situações-problema buscaram contextualizar o ensino de Ciências com as tecnologias e questões sociais, visto que entender como esses produtos funcionam pode contribuir para a conscientização sobre seu uso (BARCELLOS; COELHO, 2019). Isso significa contemplar o enfoque CTS nos currículos de Ciências que consideram o contexto da sociedade tecnológica atual e suas implicações à vida humana (SANTOS, 2007).

O tema interação RUV-corpo humano pode ser considerado um tema CTS, devido ao seu caráter sociocientífico. Para Santos e Mortimer (2009, p. 192), temas dessa natureza "[...] têm sido geralmente denominadas socioscientificissues (SSI) as quais podem ser traduzidas por questões sociocientíficas, ou temas sociocientíficos". Ainda segundo os mesmos pesquisadores, os temas sociocientíficos não precisam ser necessariamente explorados a partir de perguntas controversas, ou de tópicos do currículo escolar. A abordagem desses temas pode emergir de conteúdos problematizados culturalmente, como parte integrante do processo de reflexão sobre o papel social da ciência.

O estudo da interação RUV-corpo humano abarca saberes de diversas áreas do conhecimento, como Física, Química, Biologia e Geociências, podendo ser entendido como um tema transversal. La Taille, Souza e Vizioli (2004) entendem a transversalidade como uma abordagem didática na qual os temas são articulados com as disciplinas clássicas. Dessa forma, o currículo não sofre uma sobrecarga e pode-se mostrar aos estudantes a correlação entre as diferentes matérias e a vida cotidiana, enfatizando sua utilidade para o exercício da cidadania.

Zarth (2013) nos diz que o trabalho que visa à transversalidade deve envolver discussões sobre temas cotidianos vivenciados pelas comunidades, famílias e estudantes, com os quais se busca articular saberes de diferentes campos do conhecimento destinados à tomada de decisão consciente. A mesma pesquisadora dialoga com Busquets (2000) a fim de entender que os conteúdos curriculares formam um eixo longitudinal de áreas do conhecimento que deve ser perpassado através dos temas transversais, que precisam contemplar a sociedade e seu cotidiano.

Nesse sentido, a aula que escolhemos para análise buscou explorar, na discussão sobre o protetor solar, elementos que contemplassem essas dimensões, como o modo de aplicação e manutenção do produto, e o significado do fator de proteção solar (FPS), o qual tem influência direta em seu preço.

Uma aula embasada nesses pressupostos pode contribuir com o processo de conscientização sobre o uso desse produto, que possui relação com uma tomada de decisão. Conforme Martínez e Carvalho (2012), o ensino de Ciências que busca empoderar os estudantes para uma tomada de decisão é reconstituído como um processo de negociação entre a cultura acadêmica e a cultura dos alunos. Então, o professor precisa desenvolver estratégias que permitam o diálogo entre essas culturas no espaço de sala de aula, de modo que os discentes possam se apropriar de aspectos específicos do universo científico, ou seja, envolvê-los no processo de enculturação. 


\section{O USO DE OBJETOS MATERIAIS MEDIACIONAIS EM AULAS DE CIÊNCIAS}

O processo de enculturação dos estudantes em práticas típicas da cultura científica envolve o engajamento em diferentes formas de ação humana, como por exemplo: observar, descrever, comparar, classificar, analisar, questionar, argumentar, planejar, avaliar, generalizar, entre outras (BARCELLOS et al., 2019). Nesse sentido, Pereira e Ostermann (2012) afirmam que, para Wertsch, o desenvolvimento de determinadas habilidades específicas surge da experiência.

O ensino de Ciências deve, portanto, criar oportunidades para que os estudantes atuem com objetos materiais mediacionais, permitindo-lhes tomar consciência sobre seus usos e, assim, identificar e modificar as formas de mediação indesejáveis. Isso porque a introdução de novos objetos com vistas ao processo de enculturação, por exemplo, no contexto de uma aula de Ciências, pode transformar a ação e promover um ambiente propício a avaliação das habilidades dos agentes atuando com esses objetos materiais mediacionais (BARCELLOS et al., 2019).

Wertsch (1999) nos diz que a ação mediada pode ter múltiplos objetivos simultâneos. Isso significa que os agentes podem ter diferentes propósitos, os quais, inclusive, podem ser conflitantes. Assim sendo, o professor possui intencionalidades, as quais, por vezes, podem não se ajustar aos objetivos dos meios mediacionais. Isto tem relação com o fato de que a natureza de um objeto Ihe impõe limitações, as quais estão atreladas ao contexto histórico, o poder e as autoridades culturais. Por isso esses meios restringem e ao mesmo tempo possibilitam a ação. É importante destacar que os meios mediacionais podem ser utilizados para fins diferentes daqueles para os quais foram pensados ou produzidos, ou seja, os agentes podem ressignificá-los de acordo com seus interesses (TRAZZI, 2015).

Sobre o estudo dos agentes-agindo-com-objetos-mediadores em sala de aula, Oliveira, Sá e Mortimer (2019) investigaram a mediação de professores utilizando objetos materiais. Tal estudo se ancorou em duas propriedades da ação mediada: o conceito de affordances, que designa "as propriedades ambientais disponíveis a certo indivíduo ou espécie animal, que permitem ou restringem a sua ação" (idem, 2019, p. 253); e spin-off, que está atrelado a noção de que os objetos materiais podem ser utilizados para fins diferentes daqueles para os quais foram pensados ou produzidos (idem, 2019).

Desse estudo emergiu uma ferramenta que possibilita a análise da mediação por meio de objetos materiais. Ela foi dividia em: (i) meios que fazem uso de suporte material, que foi subcategorizado em meios que fazem uso de suporte material de projeção, de escrita e de letiura; e (ii) objetos mediadores, que foram subcategorizados em dêiticos, prototípicos, metrológicos, ressignificados e experimentais/fenomenológicos. A Figura 1 sintetiza a ferramenta supracitada.

Os resultados obtidos por Oliveira, Sá e Mortimer (2019) sinalizam para a importância de se investigar o uso de objetos mediadores por professores, dado que eles "ampliam e potencializam as qualidades dos meios mediacionais no ato de ensinar" (idem, 2019, p. 251). É diante desse cenário que propomos investigar uma aula que enfatizou os produtos de proteção à exposição ao sol (protetor solar e bronzeador), pois queremos compreender como ocorre a mediação do 
professor, em uma aula de cunho sociocientífico nos anos iniciais, no que tange o uso desses objetos materiais mediacionais.

Figura 1 - Diagrama de categorização e subcategorização dos Meios Mediacionais

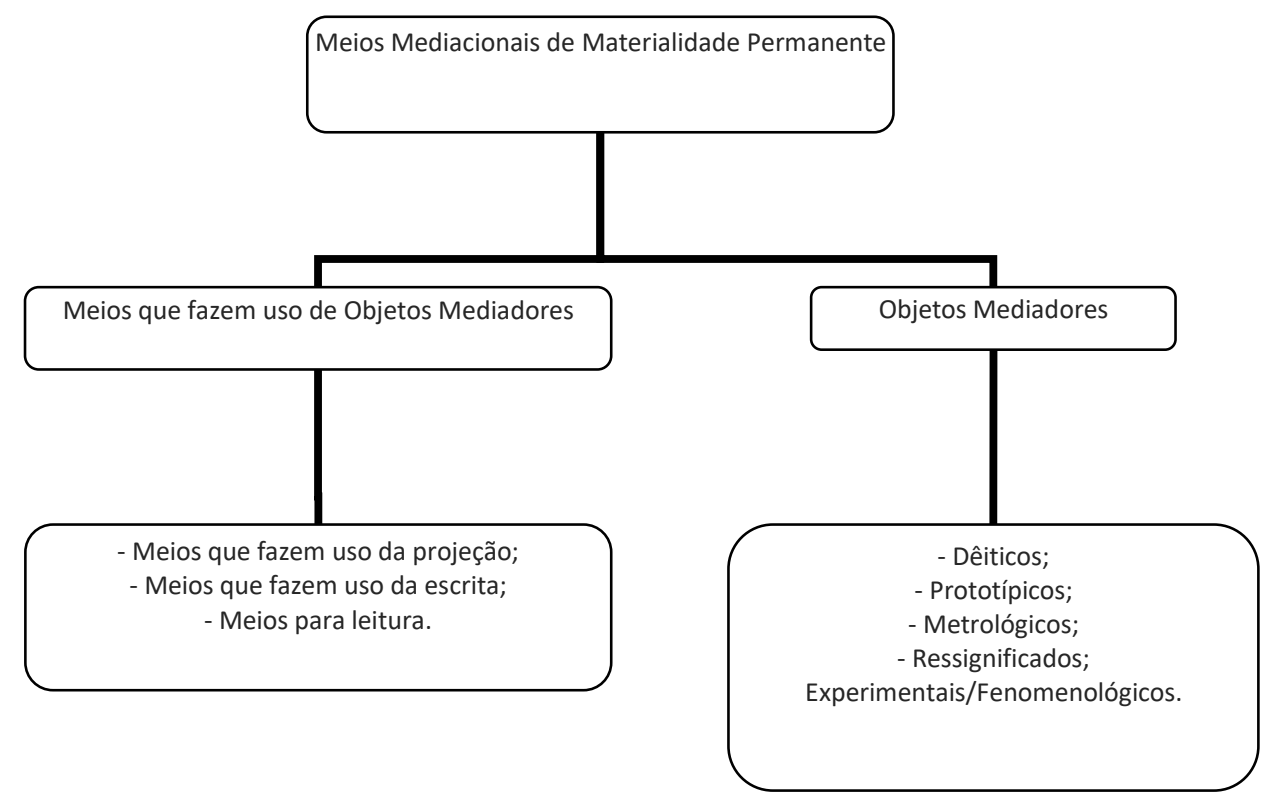

Fonte: Oliveira; Sá; Mortimer (2019).

Julgamos ser pertinente investigar esse contexto em virtude de o professor ter propósitos ao trazer determinados objetos para a sala de aula, os quais estão relacionados aos significados que ele almeja construir com os estudantes. Nesse sentido é válido caracterizar a mediação do professor, no contexto em que o uso dos objetos materiais mediacionais ocorreu, por meio da teoria da ação mediada de Wertsch (1999), destacando os cinco elementos que a compõe: (i) ato (ação), que se refere a o que ocorreu na ação ou no pensamento; (ii) cena (contexto), que representa a situação em que ocorreu; (iii) agente, que é o sujeito que realiza a ação ou o pensamento; (iv) propósito, que sinaliza para a intenção do agente; e (v) agência, que são as ferramentas socioculturais utilizadas.

Trazzi (2015) sinaliza para a importância desses elementos ao considerar que eles possibilitam a análise do contexto em que a ação mediada se delineia. Oliveira e Rodrigues (2006), ancorados em Gibson (1986), afirmam que a interação agentes-contexto pode ser compreendida por meio do conceito de affordances, que foi um dos conceitos que embasaram a análise do uso de objetos materiais e a ferramenta analítica de Oliveira, Sá e Mortimer (2019).

A partir desses elementos nos perguntamos: de que forma os objetos materiais mediacionais foram utilizados na mediação do professor? Eles foram ressignificados? Como o contexto da aula influenciou as ações realizadas?

\section{METODOLOGIA}

Realizamos uma pesquisa qualitativa e do tipo estudo de caso a partir de um recorte em uma pesquisa de mestrado profissional (BARCELLOS, 2017). Escolhemos o estudo de caso por delimitarmos as fronteiras de análise com o intuito de aprofundar nas particularidades do contexto definido: uma aula de 
Ciências, de caráter investigativo e sociocientífico, nos anos iniciais do Ensino Fundamental, a qual possui sentido singular diante da realidade (LÜDKE; ANDRÉ, 2013). Nela, buscamos descrever as ações no contexto em que ocorreram para ilustrar um tópico da investigação (YIN, 2003).

Tal pesquisa envolveu o desenvolvimento de uma sequência de ensino investigativa (SEI) (CARVALHO, 2013b) no segundo semestre de 2016 em uma turma de quinto ano dos anos iniciais do Ensino Fundamental de uma escola da rede municipal de Vitória, no Espírito Santo.

Essa intervenção foi realizada no turno vespertino, que contava com 21 alunos, sendo 12 meninos e 9 meninas. Durante todo este trabalho, os estudantes tiveram suas identidades preservadas, sendo que, para isso, nomes fictícios foram utilizados. Também foi realizado um tratamento destinado a esconder os rostos dos sujeitos nas imagens compartilhadas neste artigo, a fim de não possibilitar qualquer tipo de identificação.

Na pesquisa supracitada foi desenvolvida uma SEI sobre o tema interação radiação ultravioleta-corpo humano. Em todas as aulas, foram estruturados objetivos educacionais em termos dos conteúdos: conceitual, procedimental e atitudinal, baseado em Pozo e Gómez-Crespo (2009). Esses objetivos educacionais foram definidos tomando por base a concepção de que a aprendizagem em Ciências envolve a inserção de estudantes em uma nova cultura (uma nova forma de pensar) que tem seus próprios códigos, práticas e formas de comunicação. Por conseguinte, o conhecimento científico envolve a apropriação de conceitos, de atitudes científicas e de procedimentos por meio da linguagem.

A SEI teve um total de nove aulas, sendo que, em cinco delas, foram propostas atividades investigativas. Todas as aulas tiveram a duração de 50 minutos, as quais envolveram basicamente: (i) entendimento sobre o funcionamento do protetor solar, bronzeador e hidratante (aula analisada nesta pesquisa); (ii) discussão sobre a dissociação entre a luz visível, infravermelho e ultravioleta; (iii) investigação sobre alguns mitos relativos à RUV como: estamos protegidos da RUV na sombra? E dentro da água? E em dias nublados?; (iv) observação de células afetadas e não afetadas pela Radiação Ultravioleta (RUV); e (v) dissecação do olho de boi para investigar como a RUV pode afetar algumas estruturas do olho. Destacando a relação entre oxidação de proteínas induzida pela radiação, que contribui para a opacificação do Cristalino, resultando na doença conhecida como Catarata.

As situações-problema elaboradas para as aulas em que foram propostas as atividades investigativas estão atreladas a um tema sociocientífico central: o câncer de pele originado por exposição prolongada à radiação ultravioleta. Esse tema norteou todas as ações e estabeleceu um vínculo entre as aulas elaboradas na intervenção cujo recorte gerou esta pesquisa.

O caráter CTS assumido na SEI manifestou-se na escolha de um tema de relevância social e que está inserido na realidade dos estudantes, de modo que as investigações realizadas ao longo das aulas pudessem conduzi-los a caminhos que culminassem na adoção de um posicionamento crítico diante de uma questão social sobre as medidas protetivas relativas à exposição ao Sol, que está correlacionada aos saberes científicos da interação radiação-corpo humano. 
A aula que escolhemos para análise intitula-se "A Luz Negra", e foi a segunda aula da SEl, e a primeira na qual foi proposta uma atividade investigativa. Ela foi planejada para ser desenvolvida em uma aula e pode ser caracterizada como uma demonstração investigativa, pois envolve uma situação problema de caráter prático experimental, mas a maioria das ações de manipulação dos objetos mediadores é desenvolvida pelo professor, devido aos riscos que o manuseio indevido pode oferecer aos estudantes (CARVALHO, 2013b).

Para sua realização, os seguintes materiais foram utilizados: Braço de manequim (encapado com fita crepe e depois pintado com tinta fluorescente), lâmpada de luz negra, protetor solar, bronzeador e hidratante. A parte prática consistiu basicamente em expor o braço de manequim pintado com tinta fluorescente (comprada em casas de material de construção) à luz emitida pela lâmpada de luz negra. Ao fazer isso, a parte pintada brilhava intensamente.

Contudo, ao passar o protetor solar em algum lugar dessa área, o brilho cessa, criando uma região escura. Ao aplicar o bronzeador, nota-se certa diminuição do brilho, mas não totalmente, enquanto o hidratante não causa qualquer interferência. A radiação ultravioleta emitida pela lâmpada induz a fluorescência da tinta do braço. O protetor solar impede que a tinta receba essa radiação ao absorvê-la, deixando a região escura. O bronzeador não bloqueia com a mesma eficiência, logo, permite a passagem de certa quantidade de radiação e o hidratante não tem a capacidade de impedir a RUV de chegar até a tinta.

Do ponto de vista conceitual, o objetivo era que os alunos compreendessem a interação entre a radiação ultravioleta e os diferentes produtos de proteção e que entendessem o que é o fator de proteção solar. A demarcação dos objetivos da atividade em relação às atitudes e aos procedimentos no contexto da SEI toma como base o sistema categórico proposto por Souza Jr (2014), que tem inspiração nos pressupostos de Pozo e Gomez-Crespo (2009) sobre a natureza desses conteúdos na educação científica.

Os conteúdos atitudinais e procedimentais almejados foram: atitudinais Dialogar e respeitar as diferenças de ideias e pensamentos; e desenvolver um posicionamento crítico e investigativo perante a situação-problema; Procedimentais - Construir modelos explicativos; Elaborar hipóteses; e Testar hipóteses.

A aula foi gravada em vídeo e áudio e, posteriormente, foi submetida a um processo fidedigno de transcrição das interações discursivas, nas quais as ocorrências de linguagem coloquial foram mantidas para preservar o contexto e a autenticidade dos enunciados. A partir disso, selecionamos o que Mortimer et al. (2007, p. 31) denominam de "episódios de ensino", que podem ser entendidos como "um conjunto coerente de ações e significados produzidos pelos participantes em interação".

O critério para seleção dos episódios (estabelecidos a posteriori) foi: momentos nos quais o professor utilizou objetos materiais para mediar à interação com os estudantes. Para analisarmos a mediação estabelecida pelo docente (que é também o primeiro autor desta pesquisa) nos episódios selecionados, recorremos à teoria de Wertsch (1999). Organizamos quadros com o fluxo das interações discursivas, explicitando os cinco elementos que compõem a ação mediada: cena, agentes, ato, propósito e agência. 
Coadunando com esse referencial interpretativo, utilizamos, para complementar o processo analítico, a categorização de meios que fazem uso de suporte material e objetos mediadores proposta por Oliveira, Sá e Mortimer (2019), sintetizada na Figura 1.

É importante destacar que os resultados da análise da natureza investigativa da aula "A Luz Negra", bem como o desenvolvimento de conceitos, atitudes e procedimentos pelos sujeitos participantes da aula, foram apresentados em outro trabalho (BARCELLOS; COELHO, 2019) e, portanto, não serão reproduzidos neste artigo.

\section{RESULTADOS}

Organizamos a aula em três episódios, os quais evidenciaram o uso de objetos materiais mediacionais no decorrer da atividade investigativa de cunho sociocientífico. No primeiro e no segundo episódio o propósito do professor foi incentivar o levantamento de hipóteses e a elaboração de explicações para o fenômeno observado nas respectivas situações. No terceiro e último episódio, o professor buscou construir com os estudantes um significado para o fator de proteção solar e sua composição química.

Na primeira aula da SEI o professor solicitou aos estudantes que elaborassem um relato contando suas experiências sobre exposição ao Sol. A maioria deles apresentou situações envolvendo idas à praia com longas horas de exposição aos raios solares sem protetor solar, ocasionando queimaduras e vermelhidão. 0 relato da aluna Paloma, por exemplo, trouxe que

Perto da hora de ir embora eu vi que eu estava vermelha até que eu fui embora e chegando em casa meu corpo começava a arde [sic] aí eu me lembrei que eu tinha me esquecido de passar o protetor solar no outro dia parou de arde [sic]. Mas depois que isso aconteceu eu nunca mais me esqueci de passar o protetor solar e foi nesse dia que eu aprendi que toda vez que fomos [sic] a praia nós devemos passar o protetor solar.

Essa aula constituiu um momento para iniciar o processo de aproximação entre a experiência dos alunos com os conhecimentos científicos a serem compartilhados na sala de aula. Esse é um aspecto importante do enfoque CTS, pois nessa perspectiva a "ciência é trazida ao mundo do estudante numa base de necessidade de saber, em vez de seguir a expectativa convencional de que o estudante deve entrar no mundo da ciência para adotar a visão de um cientista" (AIKENHEAD, 2009, p. 22).

Os relatos produzidos pelos alunos sinalizaram para certa familiaridade com o protetor solar, cuja função primeira é de ser um produto para a pele. Assim sendo, a atividade almejava a apropriação e domino dessa ferramenta pelos estudantes, com vistas à tomada de decisão consciente sobre seu uso.

O professor iniciou a aula "A luz negra" organizando os alunos em semicírculo, de modo que todos pudessem ver um ao outro, e que pudessem se posicionar de forma equidistante dos materiais que seriam utilizados na atividade. Posteriormente, ele sistematizou elementos fundamentais do relato dos discentes que estavam associados ao excesso de exposição ao Sol sem proteção. No fim dessa contextualização, o professor lançou uma questão, com o 
intuito de que eles pensassem sobre o funcionamento do protetor solar, e assim se inicia o episódio 1.

\section{Episódio 1}

Quadro 1 - Interações discursivas do primeiro episódio

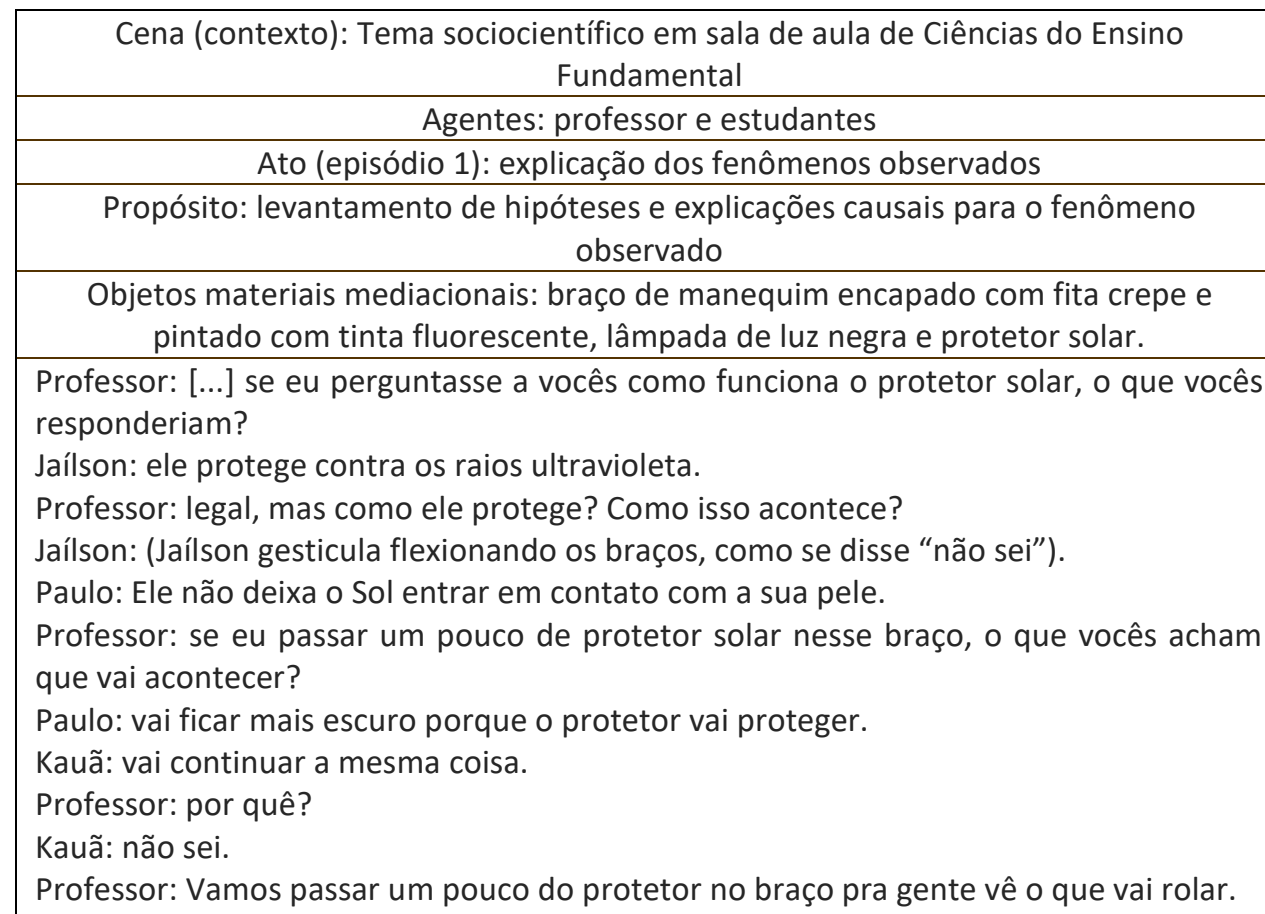

Figura 2 - Paulo realizando inferência ao aplicar o protetor solar no braço de manequim

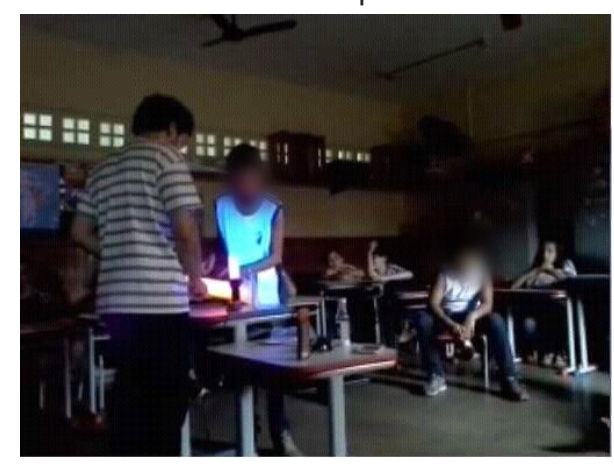

Fonte: Autoria própria (2019).

Professor: Por que onde passei o protetor ficou mais escuro?

Paulo: Porque protege dos raios ultravioleta.

(Turma em silêncio)

Professor: e aí, por que onde passei o protetor não está brilhando?

Paulo: se ele protege contra os raios do Sol, protege também contra essa lâmpada aí. Professor: Por que onde eu passei o protetor ficou escuro e o restante do braço ficou brilhando?

Mário: porque o protetor fez ele mudar de cor, os raios ultravioleta.

Jomar: eu tenho uma teoria bem simples: que o protetor solar simplesmente ele tipo faz uma espécie de camada, que protege da radiação do Sol.

Jocione: o protetor solar refletiu a luz, ele não absorveu, não deixou chegar na pele.

$$
\text { Fonte: Autoria própria (2019). }
$$


Entre os turnos 1 e 5 ocorreu um debate sobre o funcionamento do protetor solar. O aluno Jaílson introduziu um termo da cultura científica escolar que é radiação ultravioleta. Entretanto, a fala desse aluno sinaliza para uma apropriação da palavra, mas não necessariamente de seu significado conceitual, pois, até aquele momento da aula, o termo raios ultravioleta não havia sido mencionado. O termo é amplamente divulgado em diversos veículos midiáticos ao se referir à exposição ao Sol e seus riscos para venda de produtos diversos que oferecem proteção. Isso pode explicar o fato de o estudante Jaílson introduzir essa palavra ao responder o professor.

Esse foi o fio condutor utilizado pelo professor para introduzir os primeiros meios mediacionais de materialidade permanente (turno 6) ao pedir que os estudantes levantassem hipóteses (turnos 7 a 10) sobre o fenômeno envolvendo os materiais apresentados no início da aula. Então, o aluno Paulo foi convidado para realizar inferência, para que os alunos pudessem comparar suas previsões com o que efetivamente ocorreu.

A partir da classificação proposta por Oliveira, Sá e Mortimer (2019), podemos entender que, antes da ação do professor, a função do braço do manequim é representar a figura humana no contexto de uma exposição. Portanto, ele pode ser classificado como objeto mediador prototípico.

A lâmpada de luz negra utilizada na atividade tem como função primeira induzir a fluorescência, dado que ela emite radiação ultravioleta de pequena intensidade na parte do espectro próxima do violeta. É importante especificar, pois existem diferentes lâmpadas de UV, as quais emitem essa radiação em frequências distintas, e para fins específicos. Por exemplo: as lâmpadas utilizadas para desinfecção e esterilização emitem radiação na faixa do UV-C (ultravioleta tipo C), cujo comprimento de onda está na faixa de 254 nanômetros. Isto tem relação com o contexto histórico e cultural do uso da radiação ultravioleta, que passa pelo médico dinamarquês Niels R. Finsen (1860 - 1904), que foi o primeiro a empregar esse termo e a utilizar a RUV na fototerapia, principalmente com intuito de tratar a tuberculose luposa (lupus vulgaris), doença que causa dolorosas lesões na pele. Downes e Blunt que, em 1877, relataram que a luz solar possuía capacidade bactericida, mas não sabiam se essa ação vinha do calor ou de alguma outra característica. Duclaux, em 1895, e Ward, em 1892, demonstraram que a ação bactericida era causada pela radiação ultravioleta (OKUNO; VILELA, 2005).

Assim sendo, podemos classificar a lâmpada utilizada como Meio que faz uso de suporte material de observação, por entendê-la como um meio que possibilita a visualização de fenômenos que não poderiam ser observados sem o auxílio dessa ferramenta (a luz visível não tem capacidade de induzir a fluorescência).

Essa classificação também pode ser utilizada para a tinta fluorescente, cuja função, antes da ação do professor, é produzir a fluorescência a partir da exposição à radiação com energia suficiente para provocar tal efeito.

Já a fita crepe, inicialmente, tem como função fixar superfícies, não se enquadrando em nenhuma das classificações de meios mediacionais propostas por Oliveira, Sá e Mortimer (2019). Essa ausência de classificação também ocorre com o protetor solar, cuja função original é de ser um produto para a pele. 
Entre os turnos 12 e 19 o professor mediou uma discussão com os estudantes buscando a elaboração de modelos explicativos para o que foi observado na demonstração investigativa realizada. Essa observação foi possível em virtude do uso feito pelo docente dos meios mediacionais de materialidade permanente.

Na ação do professor, o braço de manequim continuou sendo utilizado para representar a figura humana, logo, sua classificação permanece como objeto mediador prototípico. O mesmo ocorreu com a lâmpada de luz negra, a tinta fluorescente e o protetor solar, cujas funções, durante a demonstração investigativa, permaneceram as mesmas. Consequentemente, as classificações desses objetos não foram alteradas.

A fita crepe, na demonstração investigativa, foi utilizada para representar a camada mais externa da derme, sobre a qual foi aplicado o protetor solar, simulando a utilização real do produto. Logo, esse meio passa a ser classificado como objeto mediador ressignificado.

Ao final do processo dialógico voltado a construir compreensão sobre o funcionamento do protetor solar, o professor realizou a etapa de sistematização e, em seguida, estabeleceu um debate com os estudantes para diferenciar este produto de outros que são utilizados na pele. Assim se iniciou o episódio 2.

\section{Episódio 2}

O professor começou problematizando o hidratante e, posteriormente, direcionou a discussão para o bronzeador. Após a discussão prévia, os estudantes foram convidados a pensar nas diferenças das propriedades do protetor e do hidratante (turnos 20 a 26).

Quadro 2 - Interações discursivas do segundo episódio

\begin{tabular}{|l|}
\hline \multicolumn{1}{|c|}{ Cena (contexto): Tema sociocientífico em sala de aula de Ciências do Ensino Fundamental } \\
\hline \multicolumn{1}{|c|}{ Ato (episódio 2): explicação dos fenômenos observados } \\
\hline \multicolumn{1}{|c|}{ Propósito: levantamento de hipóteses e explicações causais para o fenômeno observado } \\
\hline $\begin{array}{l}\text { Objetos materiais mediacionais: braço de manequim encapado com fita crepe e pintado com } \\
\text { tinta fluorescente, lâmpada de luz negra, bronzeador e hidratante. }\end{array}$ \\
\hline Professor: Qual a diferença entre um protetor solar e um hidratante qualquer? \\
Paulo: É que o hidratante não vai ter a mesma propriedade do protetor solar. \\
Professor: que propriedade é essa? \\
Paulo: eles colocam alguma coisa pra [sic] proteger. \\
Pep: qual o produto que eles colocam no protetor solar? \\
(Professor espera para ver se algum estudante propõe algo, mas a turma fica em silêncio). \\
Professor: e o bronzeador? \\
Paulo: é a mesma coisa, só que um pouco menos. \\
Professor: então vamos investigar o que acontece se eu passar esses produtos no nosso braço \\
aqui. \\
(Alunos realizam inferências juntamente com o professor) \\
Mia: o bronzeador é mais líquido, aí faz uma camada mais fina. \\
Professor: Olha, ela disse aqui que o bronzeador é mais líquido, por isso fez uma camada mais \\
fina. Foi isso que aconteceu com o braço quando eu passei o bronzeador? \\
Turma: brilhou menos! \\
Professor: e o hidratante? \\
Turma: não aconteceu nada!
\end{tabular}


No turno 27 o professor convidou os estudantes a realizarem inferências no braço do manequim, aplicando óleo bronzeador e hidratante, que foram os novos meios mediacionais de materialidade permanente utilizados na demonstração investigativa. O braço do manequim, a tinta fluorescente, a fita crepe e a lâmpada de luz negra podem ser compreendidos da mesma forma como discutido no episódio 1.

Antes da ação do professor, o óleo bronzeador e o hidratante têm como função serem produtos para a pele, não recebendo classificação na perspectiva de Oliveira, Sá e Mortimer (2019).

Entre os turnos 28 e 32, os estudantes se envolveram em uma discussão que buscava a compreensão dos fenômenos observados, os quais, mais uma vez, foram possíveis em razão da demonstração investigativa realizada. Nela, as funções do bronzeador e o hidratante não se alteraram e, por conseguinte, as classificações se mantiveram.

Após as discussões sobre os fenômenos observados, ocorreu a etapa de sistematização sobre o funcionamento dos produtos. Posteriormente o professor direcionou o foco para o fator de proteção solar contido nos rótulos do protetor solar e do bronzeador e, assim, foi iniciado o episódio 3.

\section{Episódio 3}

Quadro 3 - Interações discursivas do terceiro episódio

\begin{tabular}{|c|}
\hline $\begin{array}{l}\text { Cena (contexto): Tema sociocientífico em sala de aula de Ciências do Ensino } \\
\text { Fundamental }\end{array}$ \\
\hline Agentes: professor e estudantes \\
\hline Ato (episódio 3): problematização do fator de proteção solar (FPS) \\
\hline $\begin{array}{l}\text { Propósito: entender o significado do FPS e a composição química dos produtos } \\
\text { investigados }\end{array}$ \\
\hline Objetos materiais mediacionais: protetor solar e bronzeador. \\
\hline $\begin{array}{l}\text { Professor: No bronzeador está escrito fator de proteção } 6 \text { e no protetor } 30 \text {. O que } \\
\text { significa isso? }\end{array}$ \\
\hline Paulo: que a força... O protetor solar é bem mais forte que o bronzeador. \\
\hline Professor: mas o que você quer dizer com mais forte? \\
\hline $\begin{array}{l}\text { Paulo: mais forte assim... De te proteger do Sol. O fator } 30 \text { é bem mais forte e vai } \\
\text { proteger bem mais que o outro. }\end{array}$ \\
\hline (Turma em silêncio. Aparentemente, todos concordaram com Paulo) \\
\hline $\begin{array}{l}\text { (Professor realiza a sistematização sobre o FPS, destacando que ele está relacionado } \\
\text { ao tempo de exposição, e não a "força") }\end{array}$ \\
\hline $\begin{array}{l}\text { Professor: Mas aí você pode pensar: nossa, posso ficar } 5 \text { horas no sol e não vou me } \\
\text { queimar? }\end{array}$ \\
\hline Turma: NÃO! \\
\hline Professor: por que não? \\
\hline Paulo: porque, se você se molhar, o protetor vai sair. \\
\hline $\begin{array}{l}\text { Professor: exato! Se eu me molhar, o protetor vai sair, se você suar, passar uma } \\
\text { toalha, passar a mão no rosto... Você retira o produto, e aí a proteção vai diminuindo. } \\
\text { Lívia: quando a gente vai na praia, minha mãe fala pra passar o protetor e ficar um } \\
\text { tempo no sol pra poder secar e não sair na água. Por quê? }\end{array}$ \\
\hline
\end{tabular}

Fonte: Autoria própria (2019).

Neste episódio os meios mediacionais de materialidade permanente utilizados foram o protetor solar e o óleo bronzeador. O professor utilizou esses 
produtos para chamar a atenção dos estudantes para uma informação contida em seus rótulos, o fator de proteção solar (FPS), elemento essencial a ser analisado na escolha de um produto para proteção a pele. Com relação às funções e classificações desses meios, nota-se que elas permaneceram como discutido nos episódios 1 e 2.

\section{DISCUSSÃO}

A análise dos três episódios evidencia o uso de diferentes meios mediacionais, por parte do professor, no processo de enculturação científica dos estudantes. Ao enfocar nos objetos materiais mediacionais percebemos que eles foram essenciais no desenvolvimento das ações ocorridas durante a aula, auxiliando na contextualização de conceitos físicos, como radiação, reflexão e absorção (relativos à forma como os produtos evitam que a RUV atinja a pele), bem como o entendimento do fator de proteção solar (FPS).

Concordamos com Oliveira, Sá e Mortimer (2019) quando entendemos que a incorporação desses objetos a mediação tem relação com a experiência e a sensibilidade do professor ao prever eventuais dúvidas, por parte dos discentes, dado o grau de abstração dos conceitos trabalhados na aula analisada.

Os objetos materiais mediacionais também foram fundamentais para o desenvolvimento da mediação pautada no ensino por investigação, a qual contribuiu para tornar a aula mais dinâmica, dado que nessa abordagem as ações são centradas nos estudantes. Sem os objetos não seria possível realizar a demonstração investigativa, a qual potencializou o desenvolvimento de conceitos, atitudes e procedimentos (discutidos em BARCELLOS; COELHO, 2019). À vista disso, podemos supor que sem os objetos mediadores o professor teria dificuldade em trabalhar os conteúdos, quiçá conseguiria ensiná-los a fim de contemplar o tema central da SEI (OLIVEIRA; SÁ; MORTIMER, 2019).

No entanto, é preciso lembrar que toda ferramenta é inútil se não houver quem a opere. Isso significa que é pouco provável que ocorra ação mediada sem que haja um meio mediacional compatível com a cena e agentes capazes de utilizá-lo, o que sinaliza para a tensão irredutível entre os agentes e os meios (WERTSCH, 1999). Foi com base nesses entendimentos que analisamos o professor agindo com objetos materiais mediacionais no contexto da aula. Assim, excluímos a possibilidade de supervalorizar as contribuições que foram produzidas pelas ferramentas e as que foram produzidas pelo professor, de maneira parcial ou separada (OLIVEIRA; SÁ; MORTIMER, 2019).

Essa perspectiva possibilitou que categorizássemos os objetos materiais mediacionais, pois foi necessário comparar o uso deles, pelos agentes, antes e durante a cena em que ocorreram as ações. Uma síntese das análises dos meios mediacionais de materialidade permanente, utilizados na aula "A Luz Negra", pode ser vista no quadro 1. 
Quadro 1 - Síntese dos objetos materiais mediacionais utilizados na aula A Luz Negra

\begin{tabular}{|c|c|c|c|c|}
\hline Meios & $\begin{array}{l}\text { Função do } \\
\text { meio } \\
\text { mediacional } \\
\text { antes da } \\
\text { ação do } \\
\text { professor }\end{array}$ & $\begin{array}{l}\text { Classificação } \\
\text { do meio } \\
\text { mediacional } \\
\text { antes da } \\
\text { ação }\end{array}$ & $\begin{array}{l}\text { Função na ação do } \\
\text { professor }\end{array}$ & $\begin{array}{l}\text { Classificação do } \\
\text { meio mediacional } \\
\text { durante a ação }\end{array}$ \\
\hline $\begin{array}{l}\text { Braço de } \\
\text { manequim }\end{array}$ & $\begin{array}{c}\text { Representar } \\
\text { a figura } \\
\text { humana no } \\
\text { contexto de } \\
\text { uma } \\
\text { exposição }\end{array}$ & $\begin{array}{c}\text { Objeto } \\
\text { mediador } \\
\text { prototípico }\end{array}$ & $\begin{array}{c}\text { Representar a figura } \\
\text { humana no contexto de } \\
\text { um } \\
\text { experimento/fenômeno }\end{array}$ & $\begin{array}{l}\text { Objeto mediador } \\
\text { prototípico }\end{array}$ \\
\hline $\begin{array}{c}\text { Protetor } \\
\text { solar }\end{array}$ & $\begin{array}{l}\text { Produto para } \\
\text { a pele }\end{array}$ & $\begin{array}{c}\text { Sem } \\
\text { classificação }\end{array}$ & Produto para a pele & Sem classificação \\
\hline $\begin{array}{c}\text { Óleo } \\
\text { bronzeador }\end{array}$ & $\begin{array}{c}\text { Produto para } \\
\text { a pele } \\
\end{array}$ & $\begin{array}{c}\text { Sem } \\
\text { classificação }\end{array}$ & Produto para a pele & Sem classificação \\
\hline Hidratante & $\begin{array}{c}\text { Produto para } \\
\text { a pele }\end{array}$ & $\begin{array}{c}\text { Sem } \\
\text { classificação }\end{array}$ & Produto para a pele & Sem classificação \\
\hline $\begin{array}{l}\text { Lâmpada de } \\
\text { luz negra }\end{array}$ & $\begin{array}{l}\text { Induzir a } \\
\text { fluorescência }\end{array}$ & $\begin{array}{l}\text { Meio que } \\
\text { faz uso de } \\
\text { suporte } \\
\text { material de } \\
\text { observação }\end{array}$ & Induzir a fluorescência & $\begin{array}{l}\text { Meio que faz uso } \\
\text { de suporte } \\
\text { material de } \\
\text { observação }\end{array}$ \\
\hline $\begin{array}{c}\text { Tinta } \\
\text { fluorescente }\end{array}$ & $\begin{array}{c}\text { Produzir } \\
\text { fluorescência }\end{array}$ & $\begin{array}{l}\text { Meio que } \\
\text { faz uso de } \\
\text { suporte } \\
\text { material de } \\
\text { observação }\end{array}$ & Produzir fluorescência & $\begin{array}{l}\text { Meio que faz uso } \\
\text { de suporte } \\
\text { material de } \\
\text { observação }\end{array}$ \\
\hline Fita crepe & $\begin{array}{c}\text { Fixar } \\
\text { superfícies } \\
\end{array}$ & $\begin{array}{c}\text { Sem } \\
\text { classificação }\end{array}$ & $\begin{array}{l}\text { Representar a camada } \\
\text { mais externa da derme }\end{array}$ & $\begin{array}{l}\text { Objeto mediador } \\
\text { ressignificado }\end{array}$ \\
\hline
\end{tabular}

Fonte: Autoria própria (2019).

Dos sete objetos materiais mediacionais utilizados na aula "A Luz Negra", apenas um foi ressignificado na ação do professor: a fita crepe. As funções dadas aos outros objetos, na demonstração investigativa, foram as mesmas para as quais eles foram originalmente pensados.

O braço de manequim foi utilizado como um protótipo para representar a figura humana; a fita crepe não fixou superfícies, mas cobriu o braço de modo a representar a camada mais externa da derme; a qual foi pintada com a tinta com o intuito de possibilitar o fenômeno da fluorescência, que fora induzido pela lâmpada de luz negra, sendo que ambos são projetados para servir a esse propósito; o protetor solar, o óleo bronzeador e o hidrante atuaram como produtos para a pele, como bem são.

É importante salientar que essa mesma atividade poderia ter sido feita sem a fita crepe, pois a própria superfície do braço de manequim representaria a camada mais externa da derme. Contudo, a tinta e o protetor aplicados diretamente à superfície de gesso do manequim poderiam diminuir sua "vida útil". Por essa razão ele foi encapado com a fita, que pode ser facilmente removida e descartada, preservando o protótipo. Se a fita não tivesse sido utilizada, nenhum dos objetos materiais mediacionais da aula "A Luz Negra" teria sido ressignificado. 
Entendemos que a ausência de ressignificações tem relação direta com o contexto no qual as ações ocorreram: uma aula investigativa de cunho sociocientífico, que envolveu o processo de tomada de consciência sobre a exposição segura ao sol pelos alunos. A aula buscou a compreensão do funcionamento das medidas protetivas e as implicações relativas ao seu uso, assumindo que a apropriação desses saberes pode potencializar o processo de tomada de decisão consciente sobre a exposição segura ao Sol, com vistas à transformação do sujeito e desenvolvimento da autonomia.

Oliveira e Rodrigues (2006) nos dizem que o significado de um contexto é percebido pelos agentes e está relacionado ao que é possibilitado a eles. Assim sendo, a mediação do professor foi estabelecida de modo que os estudantes pudessem perceber a possibilidade de utilizarem o protetor solar como produto de proteção para a pele.

Para tanto, foi realizada a demonstração investigativa envolvendo os produtos de proteção, pois ao trazer os conteúdos na forma de situaçõesproblema a serem solucionados pelos estudantes agindo com os objetos materiais mediacionais, eles puderam assumir um papel ativo durante a prática, compartilhando com o professor a responsabilidade de compreender o funcionamento das medidas protetivas e as implicações relativas ao seu uso. Essa adequação, tanto da mediação, quanto da atividade, foi essencial, pois as affordances também dependem da capacidade dos agentes em percebê-las (OLIVEIRA e RODRIGUES, 2006).

O objetivo era que os alunos se apropriassem e dominassem os produtos com vistas a utilizá-los com o propósito para o qual foram construídos. Logo, foi necessária uma mediação que os ajudassem a atribuir um significado aos objetos materiais mediacionais, pois o que uma coisa "é" tem relação com o que ela "significa". No caso do protetor solar foi discutida, primeiramente, a possibilidade de ação com esse objeto, pois este é o elemento central do processo perceptivo. Posteriormente, foi contemplada sua propriedade (o fator de proteção solar FPS) (GIBSON, 1986 apud OLIVEIRA e RODRIGUES, 2006).

Esses movimentos, com vistas ao entendimento do funcionamento e do uso correto, relacionam-se a apropriação e domínio sobre esse objeto material. Dessa forma, almejava-se o desenvolvimento de habilidades para lidar com esse meio e que os estudantes tomassem para si esse elemento que, apesar de ser popularmente conhecido, não é de uso cotidiano. Consequentemente, esperavase a existência de certa resistência no processo de dominação. Por isso, é preciso reconhecer que o protetor solar, enquanto construto da ciência está associado ao poder e a autoridade que essa cultura possui (WERTSCH, 1999).

O uso dessa medida protetiva está relacionado a uma forma de se expor ao Sol, a qual entendemos como sendo um processo de tomada de decisão. Porque expor-se a radiação solar é essencial para a saúde humana, haja vista que a ativação da vitamina $D$ se inicia quando o indivíduo recebe RUV-B nos comprimentos de onda entre 290 e 315 nanômetros. A esta vitamina é atribuído o papel de regulador da fisiologia osteomineral, especialmente do metabolismo do cálcio (CASTRO, 2011).

É possível escolher diferentes modos de se expor ao sol, não sendo recomendado se abster dele, o que se relaciona com a ideia de que o ambiente natural oferece muitos modos de vida, os quais também podem ser considerados 
grupos de affordances (OLIVEIRA e RODRIGUES, 2006). Nesse sentido, a escolha por uma exposição segura perpassa o processo de tomada de consciência sobre os riscos e benefícios (ou seja, as possibilidades) da exposição à RUV solar.

Em tal processo, no enfoque CTS, o papel do professor não é apresentar já de pronto as soluções para os estudantes. Mas sim ajudá-los a perceber os critérios positivos e negativos, permitindo que eles determinem o que é inaceitável, tendo consciência dos valores que orientam a escolha (SANTOS e MORTIMER, 2001). Nesse contexto as affordances podem ser entendidas como oportunidades, cabendo ao agente decidir se deseja ou não utilizá-las (OLIVEIRA e RODRIGUES, 2006).

Assumir essa perspectiva exige a disponibilização das informações no contexto no qual elas estão ligadas, pois o comportamento dos sujeitos se relaciona a isto (OLIVEIRA e RODRIGUES, 2006). Esse entendimento corrobora a importância da contextualização das situações-problema, características do ensino por investigação. No caso da aula analisada nesta pesquisa, a contextualização foi feita por meio da articulação com o enfoque CTS, a partir de uma questão sociocientífica.

Por conseguinte, a mediação estabelecida precisa possibilitar o processo de captação dessas informações, pois é ele que permite que o agente tome consciência de si e de suas possibilidades (LOMBARDO, 1987 apud OLIVEIRA e RODRIGUES, 2006). Portanto, a mediação estabelecida pelo professor, influenciada pelo cunho sociocientífico da aula, procurou viabilizar aos estudantes a captação da possibilidade do uso dos produtos para uma exposição segura ao sol por meio da sua aplicação em um "braço" exposto ao "Sol" (o manequim exposto à lâmpada de luz negra), que é a finalidade para a qual o produto foi criado.

Diante do exposto, foi fundamental a inclusão dos produtos para pele na demonstração investigativa e seus usos da mesma forma como foram pensados, o que ratifica nosso entendimento da ausência de ressignificações em virtude do contexto da aula.

A ausência de ressignificações nos três episódios analisados não significa que o professor não percebeu outras affordances nos objetos materiais mediacionais. Um exemplo disso ocorreu no fim da aula, posteriormente ao término da investigação sobre o funcionamento dos produtos de proteção a pele. Após entregar para cada aluno um pouco de protetor solar e uma folha de papel branca, o professor pediu aos alunos que fizessem desenhos na folha utilizando o produto, para que, em seguida, estes fossem expostos à lâmpada de luz negra, com a sala previamente escurecida. Parte das produções pode ser vista na figura 3.

No contexto dessa cena, que teve um viés mais lúdico, a lâmpada de luz negra pode ser classificada como meio que faz uso de suporte material de observação, pois possibilitou a visualização do fenômeno que tornou a atividade diferente (a luz visível, por exemplo, não seria capaz de promover tal efeito). A folha de papel é utilizada normalmente para inserção de informações por meio de escrita, desenho, gráficos etc. Na ação dos agentes, ela foi utilizada nesse mesmo sentido, portanto, podemos classificá-la como meio que faz uso de suporte material de desenho. Já o protetor solar, projetado para ser um produto para a pele, foi utilizado, pelos agentes, para fazer desenhos. Portanto, ele foi 
ressignificado. A utilização de objetos na mediação para fins diferentes daqueles para os quais foram pensados ou produzidos se aproxima da propriedade spin-off da ação mediada de Wertsch (OLIVEIRA; SÁ; MORTIMER, 2019).

Figura 3 - Desenhos dos alunos expostos à lâmpada de luz negra, no momento final da aula

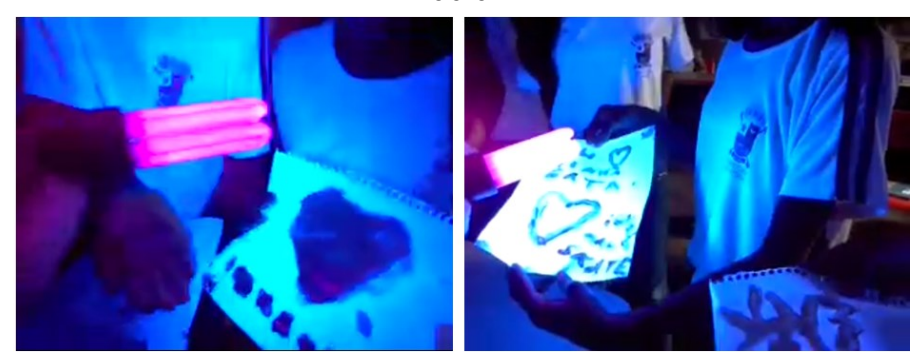

Fonte: Autoria própria (2019).

As ações desse trecho da aula não tinham compromisso com os objetivos pedagógicos estabelecidos, ou seja, a ressignificação ocorreu em um momento no qual o cunho sociocientífico foi substituído pela ludicidade. Isto também reforça nosso posicionamento sobre a influência da abordagem investigativa e do cunho sociocientífico nas affordances disponibilizadas pelo professor durante a atividade.

\section{CONSIDERAÇÕES FINAIS}

A caracterização da mediação docente, com base na teoria da ação mediada de Wertsch, enfocando no uso dos objetos materiais mediacionais, evidenciou que o emprego desses recursos auxiliou na definição das ações, na contextualização dos fenômenos e na realização da demonstração investigativa. A partir da classificação proposta por Oliveira, Sá e Mortimer (2019) notamos que os agentes utilizaram as ferramentas da forma como foram pensadas.

Atribuímos essa ausência de ressignificações ao contexto da aula investigativa e de cunho sociocientífico, que levou o professor a estabelecer uma mediação que delimitou as affordances de modo a disponibilizar para os estudantes a captação das informações sobre a possibilidade de utilização daqueles objetos materiais para o mesmo fim que foram produzidos, com vistas à apropriação e o domínio, por parte dos alunos. Isso ratifica a idiossincrasia das ações desenvolvidas, pois estamos falando de uma aula investigativa e de cunho sociocientífico nos anos iniciais do Ensino Fundamental que buscava contemplar o processo de tomada de consciência sobre a exposição a sol.

Nesse contexto, é difícil imaginar que não fosse utilizado, por exemplo, o protetor solar para mediar às ações, o que sinaliza para a importância dos objetos materiais mediacionais no processo de enculturação científica, que envolve, entre outras coisas, a apropriação dos construtos da ciência. Isto posto, questionamo-nos sobre a eficácia dessa aula caso fosse conduzida de forma majoritariamente expositiva, com apenas a linguagem como meio mediacional.

Os objetos materiais mediacionais foram fundamentais no processo de enculturação científica dos estudantes, mas essa potencialidade está condicionada a existência de agentes capazes de operá-los. Assim, reconhecemos 
a não trivialidade da inserção de recursos materiais em aulas de Ciências, bem com a necessidade de isto ser feito paralelamente com a formação docente para utilizá-los, pois a experiência e a sensibilidade do professor são elementos que influenciam na adoção desses recursos, no reconhecimento das affordances e no planejamento do que disponibilizar e em que momento.

O final da aula que analisamos aponta para essa direção, em que o professor disponibilizou outra affordance para os estudantes, quando o aspecto lúdico substituiu o cunho sociocientífico da atividade. Nele, os agentes ressignificaram o protetor solar, sinalizando para a propriedade spin-off da ação mediada de Wertsch.

Identificamos como contribuição deste estudo a obtenção de resultados, oriundos da análise realizada, que contribuem para o processo de reflexão sobre o uso de objetos materiais mediacionais que potencializam o trabalho docente em aulas de Ciências Naturais. Especialmente no que tange a relação entre o contexto da aula e as affordances e spin-off os quais, em nosso caso, foram influenciados pelo cunho sociocientífico da atividade.

Como implicações, apontamos a necessidade da realização de estudos sobre o uso de objetos materiais mediacionais no contexto de aulas orientadas pelas diferentes metodologias ou abordagens de ensino e temas. Tais estudos podem investigar questões como, por exemplo: como os objetos materiais mediacionais são utilizados na mediação do professor em aulas pautadas em uma determinada metodologia ou abordagem? Existem metodologias (ou abordagens) mais (ou menos) propícias ao uso de objetos materiais mediacionais na mediação docente? Estas e outras questões poderão ajudar a compreender a relação agentes-meios-mediacionais-metodologias/abordagens-de-ensino, com vistas a embasar decisões para o trabalho docente. 


\title{
Analysis of the use of mediational material objects in an inquiry-based science class with socio-scientific feature in elementary school
}

\begin{abstract}
This research aims to analyze the pedagogical mediation performed by a teacher during a science lesson oriented on inquiry-based teaching with socio-scientific feature, with regarding him 'actions with Mediational Material Objects. Thus, we realized a case study from an Inquiry-Based Teaching Sequence developed in the second half of the 2016, in the fifth year of Elementary Education in a public school in Vitória, Espírito Santo. The intervention addressed the theme interaction ultraviolet radiation-human body and has a transversal and socio-scientific feature, provides, therefore, an interlocution with the assumptions of the approach of Science, Technology and Society. The recording of an inquiry-based class entitled "The black light" was used as the main means of data collection. The investigative activity discussed about the different sun protection products. The recording was transcribed and qualitatively analyzed based on authors of science education anchored on Wertsch's theory of mediated action for discuss the relation between the use of cultural tools and their meanings in the teachers in action context. The results show absence of re-significances of Mediational Material Objects, which we ascribed to the socio-scientific feature of the activity. This led the teacher to determining the possibilities of action with the objects so there was no resignification, because the class discussed about the technologies presents in the daily' students, for the purpose of establishing an approach with their social reality. We consider that the results can assist to reflection process about the use of the material resources that enhance the teacher's work in socio-scientific classes.
\end{abstract}

KEYWORDS: Science Teaching. Initial years of Elementary school. Mediational Material Objects. Mediated action. Mediational means. 


\section{REFERÊNCIAS}

AIKENHEAD, G. Educação Científica para todos. 1. ed. Lisboa: Edições Pedagogo, 2009.

BARCELLOS, L. S. Ensino Da Interação Radiação-Corpo Humano nos Anos Iniciais do Ensino Fundamental: Uma Abordagem Investigativa e Colaborativa com Enfoque Ciência, Tecnologia e Sociedade. 2017. Dissertação (Mestrado em Ensino de Física) - Programa de Pós-graduação em Ensino de Física, Universidade Federal do Espírito Santo, Vitória, 2017.

BARCELLOS, L. S.; GERVÁSIO, S.; JONIS SILVA, M.; COELHO, G. A Mediação Pedagógica de uma Licencianda em Ciências Biológicas em uma Aula Investigativa de Ciências Envolvendo Conceitos Físicos. Revista Brasileira De Pesquisa Em Educação Em Ciências, Belo Horizonte, v. 19, n. 1, p. 37-65, 2019.

BARCELLOS, L. S.; COELHO, G. R. Uma análise das interações discursivas em uma aula investigativa de ciências nos anos iniciais do ensino fundamental sobre medidas protetivas contra a exposição ao sol. Investigações em ensino de ciências, Porto Alegre, v. 24, n. 1, p. 179-199, 2019.

COELHO, G. R.; AMBRÓZIO, R.M. O Ensino por investigação na formação inicial de professores de Física: Uma experiência do Residência Pedagógica de uma Universidade Pública Federal. Caderno Brasileiro de Ensino de Física, Florianópolis, v. 36, n. 1, p. 490-513, 2019.

CARVALHO, A. M. Habilidades de Professores Para Promover a Enculturação Científica. Revista Contexto \& Educação, Unijuí, v. 22, n. 77, p. 25-49, 2013 a.

CARVALHO, A. M. P. C. Ensino de Ciências por Investigação: condições para implementação em sala de aula. 1. ed. São Paulo: Cengage Learning, 2013b.

CARVALHO, A. M. P. Fundamentos Teóricos e Metodológicos do Ensino por Investigação. Revista Brasileira de Pesquisa em Educação em Ciências, Belo Horizonte, v. 18, n. 3, p. 765-794, 2018.

CASTRO, L. C. G. de. O sistema endocrinológico vitamina D. Arquivos Brasileiros de Endocrinologia e Metabologia, São Paulo, v. 55, n. 8, p. 566-575, 2011.

DRIVER, R.; ASOKO, H.; LEACH, J.; MORTIMER, E. F.; SCOTT, P. (1999). Construindo conhecimento científico em sala de aula. Química Nova na Escola, São Paulo, v. 9, n. 5, p. 31-40, 1999.

GUISSO, S. M. O ensino de ciências nos anos iniciais do ensino fundamental: um estudo das narrativas produzidas no estágio supervisionado em um curso de pedagogia no interior do estado do Espírito Santo. 2018. Dissertação (Mestrado em Educação) - Centro de Educação, Universidade Federal do Espírito Santo, Vitória, 2018. 
LA TAILLE, Y. de; SOUZA, L. S.; VIZIOLI, L. Ética e educação: uma revisão da literatura educacional de 1990 a 2003. Educação e Pesquisa, São Paulo, v. 30, n. 1, p. 91-108, 2004.

LÜDKE, M.; ANDRÉ, M. E. D. A. Pesquisa em Educação: abordagens qualitativas. 2 ed. Rio de Janeiro: EPU, 2013.

MARTÍNEZ, L. F. P.; CARVALHO, W. L. P. Contribuições e dificuldades da abordagem de questões sociocientíficas à prática de professores de ciências. Educação e Pesquisa, São Paulo, v. 38, n. 3, p. 727-741, 2012.

MORTIMER, E. F.; MASSICAME, T.; BUTY, C.; TIBERGHIEN, A. Uma metodologia para caracterizar os gêneros de discurso como tipos de estratégias enunciativas nas aulas de ciências. In: NARDI, R. A pesquisa em ensino de ciência no Brasil: alguns recortes. 1. ed. São Paulo: Escritura, 2007, p. 53-94.

OKUNO, E.; VILELA, M. A. C. Radiação Ultravioleta: Características e Efeitos. 1. ed. São Paulo: Livraria da Física, 2005.

OLIVEIRA, F. I. S.; RODRIGUES, S. T. Affordances: A relação entre agente e ambiente. Ciências \& Cognição, Rio de Janeiro, v. 9, n. 1, p. 120-130, 2006.

OLIVEIRA, L. A.; SÁ, E. F.; MORTIMER, E. F. Transformação da Ação Mediada a partir da Ressignificação do Uso de Objetos Mediadores em Aulas do Ensino Superior. Revista Brasileira De Pesquisa Em Educação Em Ciências, Belo Horizonte, v. 19, n. 1, p. 251-274, 2019.

PEREIRA, A. P.; OSTERMANN, F. A aproximação sociocultural à mente, de James V. Wertsch, e implicações para a educação em ciências. Ciência e Educação, Bauru, v. 18, n. 1, p. 23-39, 2012.

POZO, J. I.; GÓMEZ-CRESPO, M. A. G. A aprendizagem e o ensino de ciências: do conhecimento cotidiano ao conhecimento científico. 5. ed. Porto Alegre: Artmed, 2009.

SÁ, E. F.; PAULA, H. F.; LIMA, M. E. C. C.; AGUIAR JR., O. G. As características das atividades investigativas segundo tutores e coordenadores de um curso de especialização em ensino de ciências. In: VI ENCONTRO NACIONAL DE PESQUISA EM ENSINO DE CIÊNCIAS, 2007, Florianópolis, Anais [...]. Florianópolis: ENPEC, 2007. p. 1-13.

SANTOS, W. L. P. Contextualização no ensino de ciências por meio de temas CTS em uma perspectiva crítica. Ciência \& Ensino, Bauru, v. 1, n. esp., p. 1-12, 2007.

SANTOS, W. L. P.; MORTIMER, E. F. Tomada de decisão para ação social responsável no ensino de ciências. Ciência e Educação, Bauru, v. 7, n. 1, p. 95$111,2001$.

SANTOS, W. L. P.; MORTIMER, E. F. Abordagem de aspectos sociocientíficos em aulas de ciências: possibilidades e limitações. Investigações em Ensino de 
SASSERON, L. H.; CARVALHO, A. M. P. Almejando a Alfabetização Científica no Ensino Fundamental: a proposição e a procura de indicadores do processo. Investigações em Ensino de Ciências, Porto Alegre, v. 13, n. 3, p. 333-352, 2008.

SASSERON, L. H.; CARVALHO, A. M. P. Alfabetização Científica: uma revisão bibliográfica. Investigações em Ensino de Ciências, Porto Alegre, v. 16, n. 1, p. 5977, 2011.

SOUZA Jr, D. R. Ensino de Eletrodinâmica em uma perspectiva investigativa: Analisando os desdobramentos sobre a aprendizagem de estudantes. 2014. Dissertação (Mestrado em Ensino de Física) - Programa de Pós-graduação em Ensino de Física, Universidade Federal do Espírito Santo, Vitória, 2014.

TRAZZI, P. S. S. Ação mediada em aulas de biologia: um enfoque a partir dos conceitos de fotossíntese e respiração celular. 2015. Tese (Doutorado em Educação) - Programa de Pós-graduação em Educação, Universidade Federal do Espírito Santo, Vitória, 2015.

ZARTH, S. M. Temas Transversais no ensino fundamental: Educação para a Saúde e Orientação Sexual. 2013. Tese (Doutorado em Educação). Programa de Pós-graduação em Educação, Pontifícia Universidade Católica do Rio Grande do Sul, Porto Alegre, 2013.

WERTSCH, J. V. La mente enacción. 1. ed. Buenos Aires: Aique, 1999.

YIN, R. K. Estudo de Caso: planejamento e métodos. 2. ed. Porto Alegre: Artmed Editora S/A, 2003.

Recebido: 07 ago. 2019

Aprovado: 18 nov. 2019

DOI: $10.3895 /$ actio.v4n3.10476

Como citar:

BARCELLOS, L. da S.; COELHO, G. R. Análise do uso de objetos materiais mediacionais em uma aula investigativa de ciências de cunho sociocientífico nos anos iniciais do ensino fundamental. ACTIO, Curitiba, v. 4, n. 3, p. 513-535, set./dez. 2019. Disponível em: https://periodicos.utfpr.edu.br/actio. Acesso em: XXX

Correspondência:

Leandro da Silva Barcellos

Av. Fernando Ferrari, n. 514, Goiabeiras, Vitória, Espírito Santo, Brasil.

Direito autoral: Este artigo está licenciado sob os termos da Licença Creative CommonsAtribuição 4.0 Internacional. 